\title{
INFLUENCE OF SIZE AND DISTANCES BETWEEN IMPURITIES ON FATIGUE STRENGTH STRUCTURAL STEEL FOR AGRICULTURAL MACHINES
}

\author{
Tomasz Lipinski \\ University of Warmia and Mazury in Olsztyn, Poland \\ tomaszlipinski.tl@gmail.com
}

\begin{abstract}
The high-purity low carbon steel properties are influenced by the chemical composition and production technology. The morphology of impurity, its size and content is very important for the quality of high-purity steel. Hard, non-plastic microstructure of steel with impurities as non-metallic inclusions can be one of the factors that influence the fatigue strength of steel. The quantity of non-metallic inclusions results from the content of impurities in the steel, while their size, dispersion, microstructure, phase composition shape and impurity spaces are determined by the course of technological processes in liquid state. The tested material consisted of semi-finished products of highpurity, low-carbon structural steel with: boron, chromium, manganese, molybdenum, nickel and low contents sulfur and phosphorus as impurities. The experimental material obtained in industrial production consisted of structural steel obtained in three series of steel melts in furnaces: electric with desulfurized, electric with desulfurized and next argon-refined and the third series from oxygen converter with vacuum degassed of steel. The technological process consisted of two melting technologies: the first and second in a 140-ton basic industrial arc furnace and the third in a 100-ton oxygen converter. The test specimens were austenitized by treatment at temperature $880^{\circ} \mathrm{C}$ for 30 minutes. Next the samples were cooled in cold water and tempered in different temperatures: $200,300,400,500$ and $600{ }^{\circ} \mathrm{C}$ for 120 minutes and cooled on air. The fatigue strength of the samples was tested on a rotary bending machine at a frequency load 6000 rotations per minute. The present work discusses the results of changes in rotary bending fatigue strength of low carbon structural steel hardened and tempered at different temperatures as the influence of size and distance proportions between the impurities of high-purity low carbon steel.
\end{abstract}

Keywords: steel, structural steel, fatigue strength, bending fatigue, impurities.

\section{Introduction}

There are many machine elements that work with variable loads. Variable steel load causes material fatigue $[1 ; 3]$. Microcrack is formed after crossing the limit of fatigue strength. The microcrack increases along with the lifetime load of the element [4-8]. Low fatigue strength may result in damage to the working element [9-10]. The fatigue cracking results mainly from exceeding the immediate fatigue strength of the material and material imperfection [11-15]. The material imperfection mainly is caused by the production process with the effect on alloy properties in particular fatigue strength $[4 ; 16-18]$. Stochastic events are mainly methods allowing to analyse factors for crack of material under the periodically varying loads $[10 ; 19]$. The low carbon steels are polycrystalline, consisting of grains with random dimension and shape geometrically separated by grain boundaries often with precipitates forming notches. The grain boundaries themselves often have different properties than the grain that can the same influence as physical discontinuities [10;20-23]. Pollution is one of the factors commonly recognized as detrimental to fatigue strength $[12 ; 24 ; 25]$. The research results presented by many authors underline their negative impact [26-28]. World literature focuses mainly on hard, little plastic steels [7; 28-31]. There are also works analysing the impact of impurities on fatigue strength of steel with high plasticity [20; 23; 32-33]. Fatigue crack initiation and its development is strongly affected by the morphology of the microstructure and random distribution of local precipitates non-deformable phases, defects such us inclusions etc. [3436]. The effect of very small impurities on fatigue strength is investigated, too [34;36]. The impact of inclusions depends on their size. It is very difficult to divide the inclusions into dimensional groups, which is why all their dimensions are usually analysed together [10;12;13;38].

Despite the inference by many researchers about the dangers of pollution their total elimination is impossible. The main group of impurities in steel are non-metallic inclusions [26; 39-40]. The strength of their impact depends on their quality, quantity, size and distribution $[10 ; 12 ; 13 ; 37 ; 42]$. Highpurity steels contain very few inclusions $[39 ; 40]$. Their quality depends on the type and chemical composition of the product from which they were made. Thus, it remains to analyse the size and distances between the impurities [33; 36].

The aim of the present study was to simultaneously determine the influence of the size and distances between the impurities on the fatigue strength of high plasticity low carbon steel. 


\section{Materials and methods}

The tested material consisted of semi-finished products of high-purity, low-carbon structural steel with: boron, chromium, manganese, molybdenum, nickel and low contents sulfur and phosphorus as impurities. The experimental material obtained in industrial production consisted of structural steel obtained in three series of steel melts in furnaces: electric with desulfurized, electric with desulfurized and next argon-refined and the third series from oxygen converter with vacuum degassed of steel. The technological process consisted of two melting technologies: the first and second in a 140-ton basic industrial arc furnace and the third in a 100-ton oxygen converter. The test specimens were austenitized by treatment at temperature $880^{\circ} \mathrm{C}$ for 30 minutes. Next the samples were cooled in cold water and tempered in different temperatures: 200,300, 400, 500 and $600{ }^{\circ} \mathrm{C}$ for 120 minutes and cooled on air. The fatigue strength of the samples was tested on a rotary bending machine at a frequency load 6000 rotations per minute. The level of load was adapted to the mechanical properties of the tested steels represented by tempering temperature: $200{ }^{\circ} \mathrm{C}(650 \mathrm{MPa}), 300-500{ }^{\circ} \mathrm{C}$ (600 MPa), $600{ }^{\circ} \mathrm{C}(540 \mathrm{MPa})[2 ; 32-34]$.

The main fraction of non-metallic inclusions about $40 \%$ were $\mathrm{Al}_{2} \mathrm{O}_{3}$, then about $15 \% \mathrm{SiO}_{2}$, the rest with a few percent of decreasing content share respectively: $\mathrm{MnO}, \mathrm{MgO}, \mathrm{CaO}, \mathrm{FeO}$ and $\mathrm{Cr}_{2} \mathrm{O}_{3}$. The content of particles in steel after outside furnance treatment is presented in [40], the structure size in [42] and the analysis of their morphology in [13]. The distances between the impurities on fatigue strength structural steel $\alpha$ were calculated by (1) and arithmetic average impurities space $\lambda$ were calculated by (2):

$$
\alpha=\frac{\bar{d}}{\lambda},
$$

where $\bar{d}$-average diameter of impurity, $\mu \mathrm{m}$;

$\lambda$ - arithmetic average impurities space.

$$
\lambda=\frac{2}{3} \bar{d}\left(\frac{1}{V_{0}}-1\right),
$$

where $V_{0}$ - relative volume of submicroscopic impurities, $\%$.

The significance of correlation coefficients $r$ was determined on the basis of the critical value of the Student's t-distribution for a significance level $\alpha=0.05$ and the number of degrees of freedom $f=n-2$.

The critical value $\mathrm{t}_{\alpha=0.05}$ from the Student's distribution for $p=(\mathrm{n}-2)$ for tempered temperature: $200,300,400,500$ and $600{ }^{\circ} \mathrm{C}$ is 2.093 and for all tempering temperatures is 1.980 . The error of measuring physical quantities did not exceed $5 \%$.

\section{Results and discussion}

The real average chemical composition of the 14 heats melted in the arc furnace and 7 in the oxygen converter tested steel are presented in Table 1.

Real chemical composition of the tested steel

Table 1

\begin{tabular}{|c|c|c|c|c|c|c|c|c|}
\hline $\mathbf{C}$ & $\mathbf{B}$ & $\mathbf{N i}$ & $\mathbf{M n}$ & $\mathbf{C r}$ & $\mathbf{M o}$ & $\mathbf{S i}$ & $\mathbf{S}$ & $\mathbf{P}$ \\
\hline 0.24 & 0.003 & 0.49 & 1.19 & 0.51 & 0.24 & 0.25 & 0.013 & 0.02 \\
\hline
\end{tabular}

Fatigue strength tested with rotary bending tested steel after hardened and tempered at: $200{ }^{\circ} \mathrm{C}$ as a function size and distances between the impurities is presented in Fig. 1 and its regression equation and correlation coefficients $r$ at (3), $300{ }^{\circ} \mathrm{C}$ are presented in Fig. 2 and its regression equation and correlation coefficients $r$ at (4), $400^{\circ} \mathrm{C}$ are presented in Fig. 3 and its regression equation and correlation coefficients $r$ at $(5), 500^{\circ} \mathrm{C}$ are presented in Fig. 4 and its regression equation and correlation coefficients $r$ at $(6), 600^{\circ} \mathrm{C}$ are presented in Fig. 5 and its regression equation and correlation coefficients $r$ at (7), all tempered temperatures (from 200 to $600{ }^{\circ} \mathrm{C}$ ) are presented in Fig. 6 and its regression equation and correlation coefficients $r$ in (8). 
Based on the analysis of the results, it was found that the analysed relationships can be presented with a linear function. The analysis of statistical parameters confirms that fatigue strength is dependent on $\alpha$, has an independent distribution and can be examined with the functions of mathematical statistics. Analysing the mathematical matches of regression equations for particular tempering temperatures, the increase of the $\alpha$ coefficient along with the lowering of the tempering temperature was found. According to the theory, along with the increase of the tempering temperature, the steel becomes plastic and therefore the matrix for non-metallic inclusions.

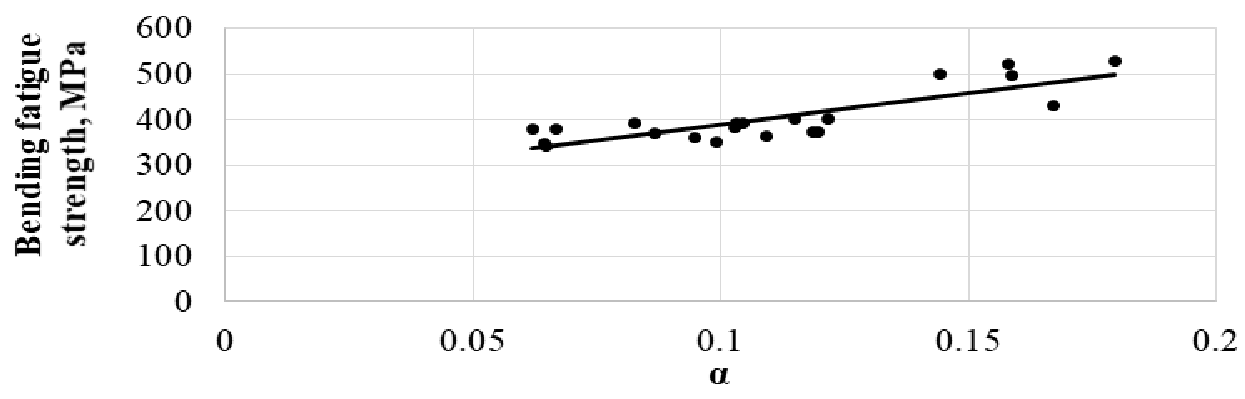

Fig. 1. Bending fatigue strength of steel hardened from $880{ }^{\circ} \mathrm{C}$ and tempered at $200{ }^{\circ} \mathrm{C}$ subject to size and distances between impurities

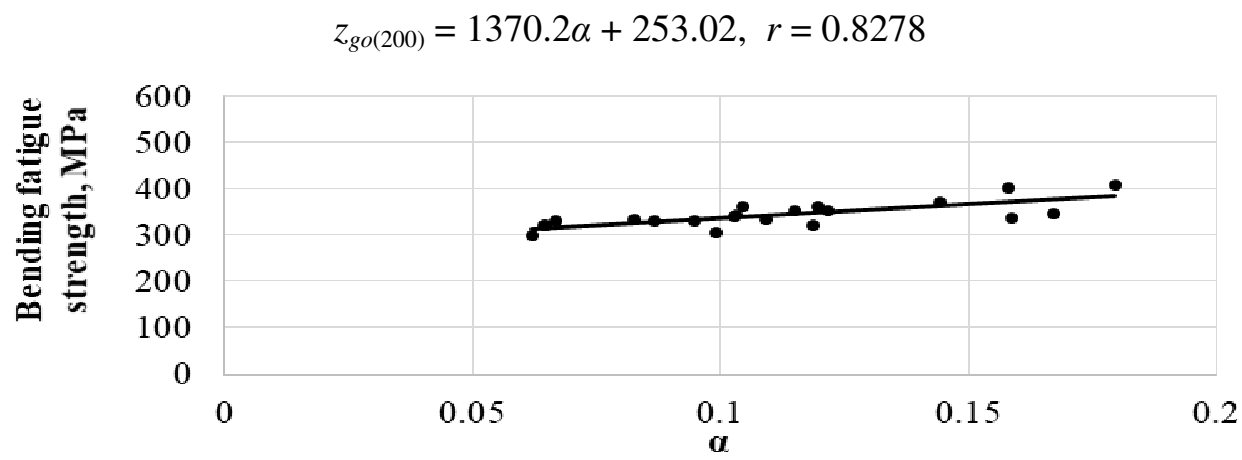

Fig. 2. Bending fatigue strength of steel hardened from $880{ }^{\circ} \mathrm{C}$ and tempered at $300{ }^{\circ} \mathrm{C}$ subject to size and distances between impurities

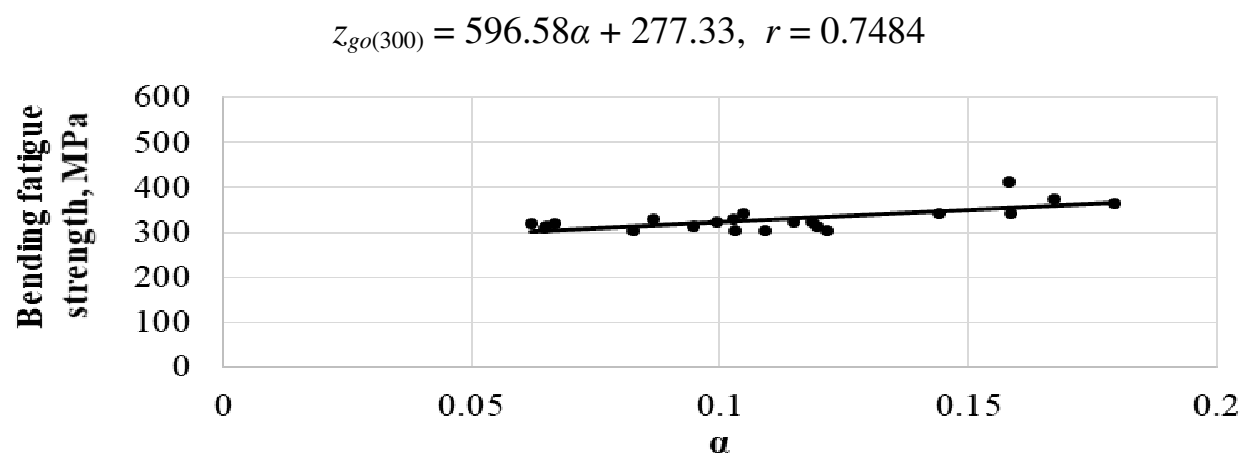

Fig. 3. Bending fatigue strength of steel hardened from $880^{\circ} \mathrm{C}$ and tempered at $400{ }^{\circ} \mathrm{C}$ subject to size and distances between impurities

$$
z_{\text {go(400) }}=537.37 \alpha+269.5, r=0.6879
$$

On this basis, it can be concluded that with the increase of hardness of steel, the effect of impurities on fatigue strength is described with greater accuracy. The directional coefficient of the regression equation is also greater. It can be concluded on this basis that also the impact of pollution on fatigue strength is more important (accelerates the destruction of the material). This statement justifies the researchers' interest in studying the impact of impurities on the strength of hard steels.

For the tempering temperatures of 300 and $400{ }^{\circ} \mathrm{C}$, for low $\alpha$ fatigue strength is comparable. It decreases for a temperature of $500^{\circ} \mathrm{C}$ by about $50 \mathrm{MPa}$ and for $600^{\circ} \mathrm{C}$ by another $50 \mathrm{MPa}$, and in relation to the tempering temperature of $400{ }^{\circ} \mathrm{C}$ by about $100 \mathrm{MPa}$. The conclusion is that the impact 
of inclusions of various sizes (large, medium, small) on fatigue strength depends on the plasticity of the matrix (steel microstructure). Analyzing the influence of impurities on steel fatigue strength after all types of tempering (Fig. 6), it was found that all statistical parameters are the average of parameters for individual microstructures represented by tempering temperatures. This equation is also statistically significant. Despite this, the extreme position of the measurement points is significantly distant from the regression line. Thus, using this regression equation (skipping the tempering temperature, and thus the microstructure of steel) only fatigue resistance of steel can be estimated. This equation can be used for estimation and accurate calculations for tempering in the range of 150$250^{\circ} \mathrm{C}$.

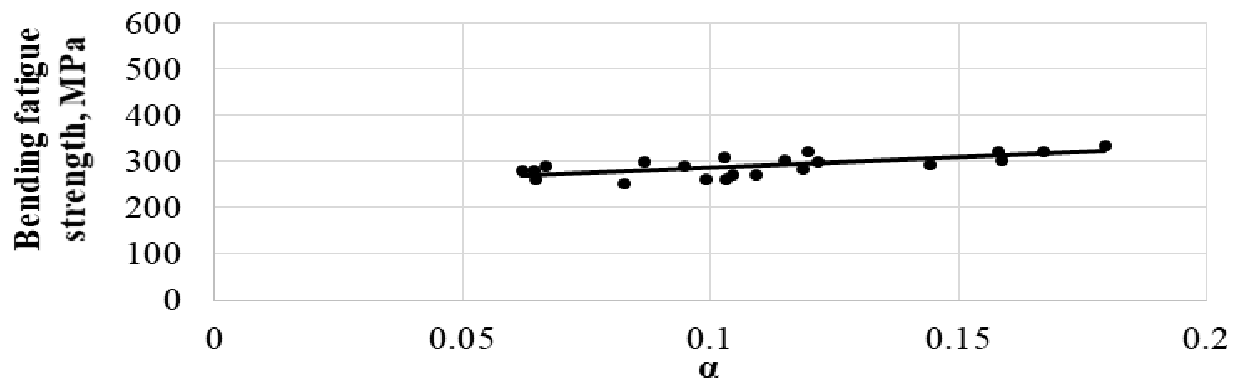

Fig. 4. Bending fatigue strength of steel hardened from $880^{\circ} \mathrm{C}$ and tempered at $500{ }^{\circ} \mathrm{C}$ subject to size and distances between impurities

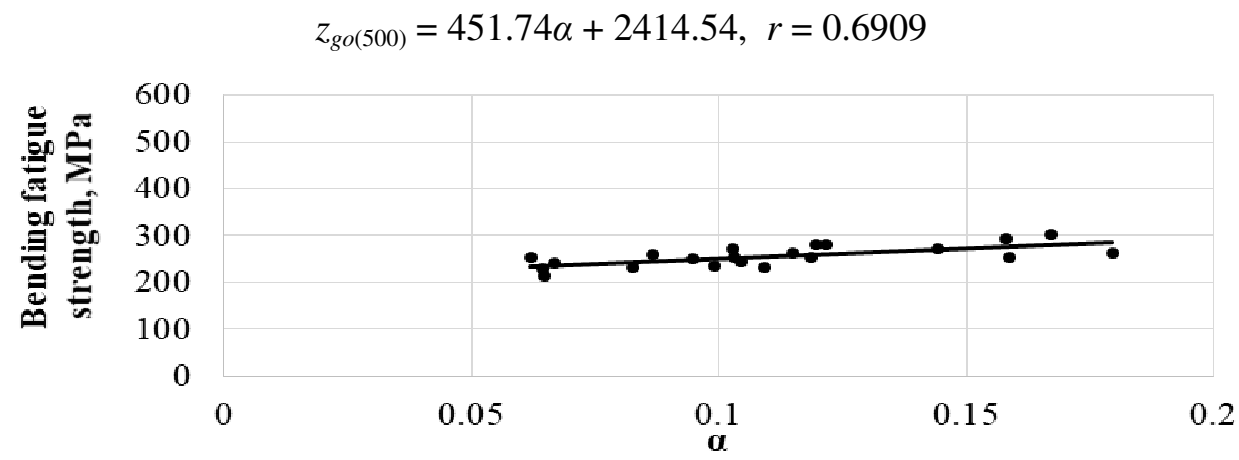

Fig. 5. Bending fatigue strength of steel hardened from $880^{\circ} \mathrm{C}$ and tempered at $600{ }^{\circ} \mathrm{C}$ subject to size and distances between impurities

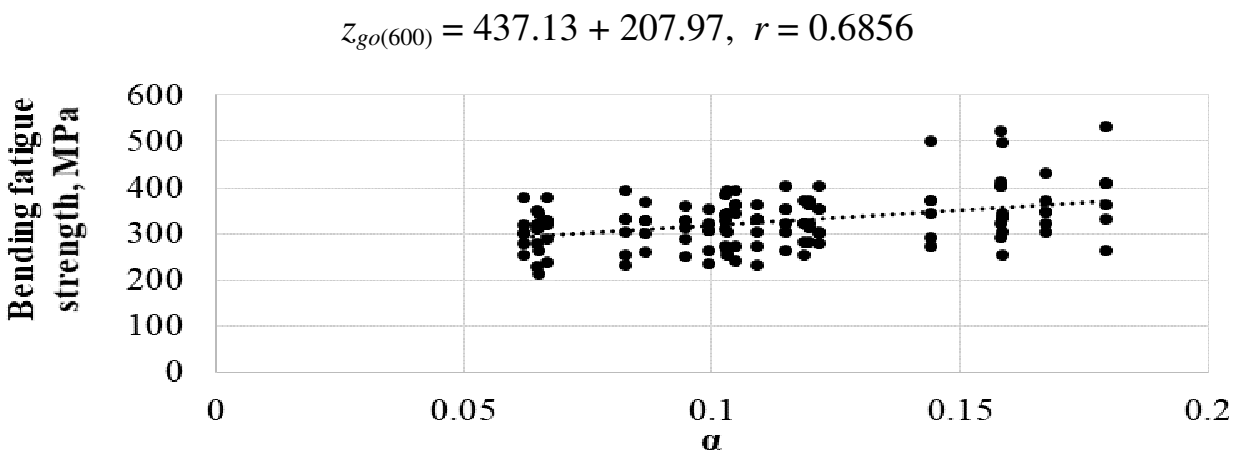

Fig. 6. Bending fatigue strength of steel hardened from $880^{\circ} \mathrm{C}$ and tempered at $200,300,400$, 500 and $600{ }^{\circ} \mathrm{C}$ subject to size and distances between impurities

$$
z_{g o(200-600)}=678.6 \alpha+249.87, r=0.3837
$$

\section{Conclusions}

1. The $\alpha$ indicator introduced reflects well the impact of impurities on the fatigue strength of steel.

2. The influence of impurities on the fatigue strength of steel depends on its tempered temperature.

3. With the increase of tempering temperature (the same as the plasticity) of steel (matrix of impurities), the impact of impurities is less intense. 
4. For steel tempered at high temperatures (500-600) the effect of the alpha parameter on the fatigue strength of steel is small.

5. The steel tempered at $200{ }^{\circ} \mathrm{C}$ is sensitive to the $\alpha$ parameter. With the increase of the tempering temperature, and thus the increase of the steel plasticity, the impact of the size and distances between the impurities on fatigue strength decreases.

\section{References}

[1] Campbell G.S., Lahey R. A survey of serious aircraft accidents involving fatigue fracture. International Journal of Fatigue 6, 1984, pp. 25-30.

[2] Suresh S. Fatigue of Materials. Cambridge University Press: Cambridge, UK, 1998.

[3] Bokůvka O., Jambor M., Nový F., Trško L., Lago J. Influence of long-term heating on the fatigue properties of low-alloyed cast steel STN 42 2707. Production Engineering Archives 12(3), 2016, pp. 30-33.

[4] Lankford J. Initiation and early growth of fatigue cracks in high strenght steel, Engineering Fracture Mechanics 9, 1977, pp. 617-624.

[5] Kerscher E., Lang K.H., Vöhringer O., Löhe D. Increasing the fatigue limit of a bearing steel by dynamic strain ageing. International Journal of Fatigue 30, 2008, pp. 1838-1842.

[6] Sangid M.D. The physics of fatigue crack initiation, International Journal of Fatigue. 57, 2013, pp. 58-72.

[7] Ulewicz R., Novy, F. Fatigue Life Of High Strength Steel For Cold Forming Metalurgija 56(1-2), 2017, 115-118.

[8] Studený Z., Dobrocky D., Pokorny Z. Importance of Diffusion Process on the Fatigue Life of Steel Manufacturing Technology 17(1), 2017, pp. 94-99.

[9] Kłysz S. Selected problems of fatigue of materials and constructions elements. Technical Science 8, 2005, pp. 141-164.

[10] Halford G. L. Low cycle thermal fatigue. NASA 1986.

[11] Ivanytskyj Y.L., Lenkovskiy T.M., Molkov Y.V., Kulyk V.V., Duriagina Z.A. Influence of 65G steel microstructure on crack faces friction factor under mode ii fatigue fracture. Archives of Materials Science and Engineering 82(2), 2016, pp. 49-56.

[12] Murakami Y., Kodama S., Konuma S., Quantitative evaluation of effects of non-metallic inclusions on fatigue strength of high strength steels, I: basic fatigue mechanism and fatigue fracture stress and the size and location of non-metallic inclusions, International Journal of Fatigue 11(5), 1989, pp.291-298.

[13]Lipiński T., Morphology of impurities in steel after desulfurization and vacuum degassing. 14 ${ }^{\text {th }}$ International Scientific Conference Engineering for Rural Development Proceedings vol. 14, Jelgava, 20.-22.05.2015, pp. 795-780.

[14] Wolczynski W. Inverse Model for The Solute Micro-Field Formation During Self-Propagating High Temperature Reaction. Archives of Metallurgy and Materials 62(1), 2017, pp. 141-147.

[15] Hua L., Deng S., Han X., Huang S. Effect of material defects on crack initiation under rolling contact fatigue in a bearing ring, Tribology International 66, 2013, pp. 315-323.

[16]Foletti S., Beretta S., Tarantino M. G. Multiaxial fatigue criteria versus experiments for small crack under rolling contact fatigue, Int. Journal of Fatigue 58, 2014, pp. 181-182.

[17] Roiko A., Hänninen H., Vuorikari H., Anisotropic distribution of non-metallic inclusions in a forged steel roll and its influence on fatigue limit, International J. of Fatigue 41, 2012, 158-167.

[18]Závodská D., Guagliano M., Bokůvka O., Trško L. Effect of Shot Peening on the Fatigue Properties of 40NiCrMo7 steel. Manufacturing Technology 16(1), 2016, pp. 299-304.

[19] Murakami Y., Nomoto T., Ueda T. Factors influencing the mechanism of super long fatigue failure in steels. Fatigue \& Fracture of Engineering Materials \& Structures 22, 1999, pp.581-590.

[20]Zrnik J., Pippan R., Scheriau S., Kraus L., Fujda M. Microstructure and mechanical properties of UFG medium carbon steel processed by HPT at increased temperature. Journal of Material Science 45, 2010, pp. 4822-4826.

[21] Bydałek A.W., Wołczyński W., Bydałek A., Schlafka P., Kwapisiński P. Analysis Of Separation Mechanism Of The Metallic Phase of Slag in The Direct-To-Blister Process. Archives of Metallurgy and Materials 60(3), 2015, pp. 2347-2353. 
[22] Palček P., Oravcová M., Chalupová M., Uhríčik M. The Usage of SEM for Fatigue Properties Evaluation of Austenitic Stainless Steel AISI 316L. Manufacturing Technology 16(5), 2016, pp. 1110-1115.

[23] Kim H.K., Choi M.I., Chung, C-S., Shin, D.H. Fatigue crack growth behavior in ultrafine grained low carbon steel. KSME International Journal 16, 2002, pp. 1246-1252.

[24]Lipiński T., Wach A., Detyna E. Influence of Large Non-Metallic Inclusions on Bending Fatigue Strength Hardened and Tempered Steels. Advances in Materials Science 15/3 (45), 2015, pp. 33-40.

[25]Zhang J. M., Zhang J. F., Yang Z. G., Li G. Y., Yao G., Li S. X., Hui W. J., Weng Y. Q., Estimation of maximum inclusion size and fatigue strength in high-strength ADF1 steel. Material. Science and Engineering A 394, 2005, pp. 126-131.

[26] Park J. S., Park J. H., Effect of Slag Composition on the Concentration of Al2O3 in the Inclusions in Si-Mn-killed Steel. Metallurgical and Materials Transactions B 45B, 2014, pp. 953-960.

[27] Murakami Y., Kodama S., Konuma S. Quantitative evaluation of effects of non-metallic inclusions on fatigue strenght of high strength steels. International Journal of Fatigue 11, 1989, pp. 291-298.

[28]Liu Y. B., Yang Z. G., Li Y. D., Chen S. M., Li S. X., Hui W. J., Weng Y.Q., Dependence of fatigue strength on inclusion size for high strength steels in very high cycle fatigue regime. Material Sciences and Engineering A 517, 2009, pp. 180-184.

[29] Mitchell M.R. Fundamentals of Modern Fatigue Analysis for Design, Fatigue and Fracture 19, ASM Handbook, ASM International, 1996.

[30] Nishijima S., Kanazawa K. Stepwise S-N curve and fish-eye failure in gigacycle fatigue. Fatigue Fatigue \& Fracture of Engineering Materials \& Structures 22, 1999, pp. 601-607.

[31] Belan J., Jambor M., Kuchariková L., Tillová E., Chalupová M., Matvija M. The SEM Investigation of Inconel 718 Fatigue Process at Various Loading Conditions Manufacturing Technology 17(5), 2017, pp. 658-665.

[32] Lipiński T., Wach A., Effect of the impurities on the bending fatigue strength of structural steel. $14^{\text {th }}$ International Scientific Conference Engineering for Rural Development Proceedings vol. 14, Jelgava, 20.-22.05.2015, pp. 784-789.

[33]Lipiński T., Wach A., Effect Size Proportions and Distances between the Non-metallic Inclusions on Bending Fatigue Strength of Structural Steel. $24^{\text {td }}$ International Conference on Metallurgy and Materials Metal 2015 Brno TANGER Ltd., Ostrava. Conference proceedings (2015) 754-760.

[34] Chan K. S. Roles of microstructure in fatigue crack initiation, International Journal of Fatigue 32, 2010, pp. 1428-1447.

[35]Lipiński T., Effect of the Spacing Between Submicroscopic Oxide Impurities on the Fatigue Strength of Structural Steel. Archives of Metallurgy and Materials 60(3b), 2015, pp. 2385-2390.

[36] Srivastava A., Ponson L., Osovski S., Bouchaud E., Tvergaard V., Needleman A., Effect of inclusion density on ductile fracture toughness and roughness. Journal of the Mechanics and Physics of Solids 63, 2014, pp. 62-79.

[37] Murakami Y., Metal fatigue. Effects of small defects and inclusions. Elsevier 2002.

[38] Chapetti MD, Tagawa T, Miyata T., Ultra-long cycle fatigue of high-strength carbon steels. Part II: estimation of fatigue limit for failure from internal inclusions. Material Science Engineering A 356, 2003, pp. 236-244.

[39]Lipiński T., Wach A., Influence of Outside Furnace Treatment on Purity Medium Carbon Steel. $23^{\text {rd }}$ International Conference on Metallurgy and Materials Metal 2014 Brno TANGER Ltd., Ostrava. Conference proceedings (2014) pp. 738-743.

[40] Gulyakov V. S., Vusikhis A. S., Kudinov D. Z., Nonmetallic Oxide Inclusions and Oxygen in the Vacuum_Jet Refining of Steel. Steel in Translation 42 (11), 2012, pp. 781-783.

[41] Lipiński T., Wach A., Dimensional Structure of Non-Metallic Inclusions in High-Grade Medium Carbon Steel Melted in an Electric Furnace and Subjected to Desulfurization. Solid State Phenomena 223. 2015, pp. 46-53. Trans Tech Publications, Switzerland.

[42] Lenkovskiy T.M., Kulyk V.V., Duriagina Z.A., Kovalchuk R.A., Topilnytskyy V.H., Vira V.V., Tepla T.L. Mode I and mode II fatigue crack growth resistance characteristics of high tempered 65G steel. Archives of Materials Science and Engineering, 84 (1), 2017, pp. 34-41. 